\title{
OS BAIRROS DO BRÁS E BOM RETIRO E A METRÓPOLE INFORMACIONAL ${ }^{1}$
}

\author{
THE NEIGHBORHOODS OF BRÁS AND BOM RETIRO AND \\ THE INFORMATIONAL METROPOLIS
}

\author{
LES QUARTIERS BRÁS ET BOM RETIRO ET LA MÉTROPOLE \\ INFORMATIONNELLE
}

Silvana Cristina da Silva - Universidade Federal Fluminense - Campos dos Goytacazes - Rio de Janeiro - Brasil
silvanasilva@id.uff.br

\section{Resumo}

A metrópole de São Paulo destaca-se no território brasileiro pelo seu poder de atração de fixos e fluxos. Ela conforma-se como central do ponto de vista da produção, organização e distribuição de informação. Daí a denominação metrópole informacional. Entretanto, apresentamos neste artigo alguns elementos da metrópole de São Paulo, como as transformações dos bairros do Brás e Bom Retiro ao longo do tempo, indicando que a metrópole continua sendo centro de produção fabril, inclusive de ramos tradicionais. Esses bairros, apesar da obsolescência para as atividades quaternárias, são lugares dinâmicos e atraem fluxos de todo o território nacional, em virtude da especialização produtiva no ramo do vestuário, destacadamente nas etapas da costura e do comércio. Dessa forma, objetivamos mostrar que o envelhecimento dos primeiros bairros da metrópole não significou decadência ou deterioração perante os novos papéis da metrópole de São Paulo.

Palavras-chave: Brás e Bom Retiro, São Paulo, metrópole informacional, circuito inferior.

\begin{abstract}
The metropolis of São Paulo stands out in Brazil for its power to attract assets and flows. São Paulo is central from the viewpoint of production and distribution of information. Hence the designation: informational metropolis. However, in this paper we present several elements of the metropolis of São Paulo, such as the transformations of the neighborhoods of Brás and Bom Retiro over time, indicating that the metropolis continues to be the center of industrial production, even in traditional fields. The neighborhoods of Brás and Bom Retiro, despite the obsolescence for quaternary activities, are dynamic places and attract flows from across the nation in virtue of the production specialization in the garment industry, notably in the stages of sewing and trade. Thus, our aim was to show that the aging of the first neighborhoods of the metropolis did not mean decay or deterioration visà-vis the new roles of the metropolis of São Paulo.
\end{abstract}

Key words: Brás and Bom Retiro, São Paulo, informational metropolis, lower circuit.

\section{Résumé}

La métropole de São Paulo se distingue du reste du territoire brésilien par son pouvoir d'attraction de biens de capital fixe et de flux. São Paulo revêt donc un rôle de centralisateur de la production, de l'organisation et de la distribution de l'information; d'où sa dénomination de métropole informationnelle. Cependant, notre article se concentrera davantage sur certains aspects de la métropole de São Paulo liés aux transformations au cours du temps des quartiers Brás et Bom Retiro indiquant que la métropole demeure le centre de production industrielle, mais aussi le centre des branches traditionnelles. En dépit du caractère obsolète des activités de secteur quaternaire de Brás et Bom Retiro, ces quartiers demeurent dynamiques et attirent les flux du Brésil tout entier du fait de la spécialisation de la production du secteur vestimentaire et plus particulièrement des étapes de la confection et du commerce. Ainsi, notre objectif est de montrer que le vieillissement des premiers 
quartiers de la métropole ne signifie pas une décadence ou une détérioration au regard des nouveaux rôles de la métropole de São Paulo.

Mots-clés: Brás et Bom Retiro, São Paulo, métropole informationnelle, circuit inférieur.

\section{Introdução}

A compreensão das funções urbanas dos bairros nas cidades relaciona-se com o papel das cidades na divisão territorial do trabalho. O Brás e o Bom Retiro nasceram com papéis específicos na cidade de São Paulo e foram transformados ao longo da formação territorial da metrópole. Contudo, apesar da retórica da deterioração do centro antigo da cidade, apresentamos, neste texto, a possibilidade de novos olhares. O Brás e o Bom Retiro, do ponto de vista da economia urbana, são tão significativos para a conformação da metrópole quanto os bairros mais jovens como a área do quadrante Sudoeste, onde se localiza a Avenida Luis Carlos Berrini, expressão máxima da cidade informacional.

A cidade, segundo Sposito (1999), é expressão do processo de urbanização. Deriva simultaneamente dos papéis urbanos desempenhados no decorrer do tempo histórico e condiciona as práticas sociais, de diferentes naturezas, que se realizam por meio do cotidiano. A autora ressalta que os papéis urbanos se tornaram mais diversos e complexos. No entanto, a concentração continua sendo uma marca das cidades, pois as formas de centralização econômica e de gestão política e financeira se realizam nas cidades. As mudanças ocorreram no plano territorial, havendo um rompimento da continuidade do tecido urbano e a acentuação do processo de periferização.

No caso do tecido urbano da cidade de São Paulo, houve um intenso processo de periferização, em virtude da valorização desigual do solo urbano, dos processos clássicos de especulação imobiliária e da expulsão de atividades industriais e de residência para bairros mais distantes. Os centros modificam suas funções urbanas, entretanto, continuam sendo dinâmicos e fundamentais para as cidades. O funcionamento da cidade de São Paulo articula-se com a economia global e com o papel que ela exerce na divisão territorial do trabalho. São Paulo revela a acumulação desigual de tempos, por isso é complexa, dinâmica e oferece uma infinidade de possibilidades de atividades produtivas para os distintos grupos sociais que constituem a vida da metrópole. A análise da formação territorial do Brás e do Bom Retiro indica o dinamismo das atividades vinculadas ao 
ramo do vestuário, especialmente caracterizadas como do circuito inferior da economia urbana ${ }^{2}$ (Santos, 2004), em que a Feira da Madrugada é exemplar.

Os distintos bairros que compõem São Paulo são articulados por fixos e fluxos que criam centralidades específicas na cidade. No caso do Brás e do Bom Retiro, houve a formação da especialização produtiva na fabricação e no comércio de vestuário (varejo e atacado). Para a compreensão desses fenômenos, apresentamos uma breve revisão da formação desses bairros, com ênfase nas atividades de pequena dimensão, que têm baixo uso de capital e tecnologia e uso de mão de obra intensiva, especialmente do circuito espacial de produção do vestuário, e caracterizadas como circuito inferior da economia urbana. Em um segundo momento, expomos alguns dados que mostram certa desconcentração da produção do vestuário no Brasil, no estado de São Paulo e na metrópole de São Paulo, mas destacamos a permanência da centralidade dessa atividade para a metrópole e para o território nacional, o que coloca em evidência a importância dos bairros antigos como Brás e Bom Retiro para a metrópole informacional.

Brás e Bom Retiro: as funções urbanas

O Brás e o Bom Retiro nasceram como chácaras e tornaram-se bairros tradicionais e importantes por terem sido abrigo da primeira fase da industrialização da cidade. Houve muitas transformações territoriais na cidade de São Paulo no século XX e início do século XXI e os bairros antigos passaram a cumprir novos papéis na metrópole informacional.

A metropolização de São Paulo, baseada na expansão da área urbana, promoveu o processo de "deterioração" do meio construído do Brás e Bom Retiro. Contudo, esses bairros criaram na obsolescência a possibilidade profícua de abrigo de uma forte especialização produtiva, ou seja, novos papéis urbanos foram assumidos por esses fragmentos da cidade.

A “deterioração" do meio construído (Harvey, 1982) é parte do próprio fenômeno de modernização e expansão da cidade, pois a modernização das atividades econômicas exige novos sistemas técnicos, juntamente a esse processo, agem os atores da especulação imobiliária, explicando o movimento intenso de obsolescência e abandono dos bairros na cidade. Montenegro $(2006,2009)$ afirma que o circuito inferior na cidade de São 
Paulo tem no meio construído deteriorado e na grande quantidade de fluxos das áreas centrais uma verdadeira economia de aglomeração para o desenvolvimento das suas atividades.

Silva Bernardes (2001) indica três recortes espaçotemporais-chave para a cidade de São Paulo, que contribuem com a formação e afirmação de sua centralidade como metrópole informacional no território brasileiro. O primeiro período compreende o final do século XIX até 1945; o segundo vai de 1945 a 1970/1980 e o período recente, compreendendo da década de 1980 até o período atual, cujo conteúdo confere o caráter de metrópole informacional. A autora, com base em Santos (2009), destaca que não há grandes rupturas desses "momentos histórico-territoriais" e estes têm como base os três elementos definidores da vida de relações ${ }^{3}$ na metrópole no território nacional: o comércio, a indústria e a informação. A expansão da mancha urbana da cidade de São Paulo tornou mais complexa a análise da articulação entre os diferentes espaços que compõem a vida urbana na metrópole. Os bairros do Brás e Bom Retiro, por exemplo, exerceram funções urbanas distintas e se consolidaram como áreas de especialização produtiva, com forte centralidade no território nacional decorrente das atividades de confecção e comércio do vestuário.

Dentro dos grandes momentos territoriais da metrópole, o Brás e o Bom Retiro apresentam algumas especificidades; por isso, com base em alguns autores (Langenbuch, 1971; Martin, 1984; Martin e Frugóli Jr., 1992; Andrade, 1994) e pesquisa de campo, identificamos cinco grandes períodos significativos para a vida de relações desses bairros: 1) o período dos "bairros das chácaras" (de 1850 a 1889); 2) o período "dos bairros operários" (de 1889 a 1930); 3) o período da "decadência industrial" dos bairros (de 1930 a 1950);4 4) o período de consolidação da especialização no circuito espacial de produção de confecções (de 1950 a 1980) e 5) o período da reorganização do circuito espacial de confecções (de 1980/1990 até os dias atuais).

No período dos "bairros das chácaras" (1850 a 1889), no Brás e no Bom Retiro, houve o predomínio das chácaras e de uma vida marcada por elementos rurais (Figura1). Além de abastecer a cidade com o fornecimento de frutas, esses bairros eram lugares de descanso das elites em formação da cidade de São Paulo.

No segundo período, "dos bairros operários" (de 1889 a 1930), a industrialização - com base na indústria, alimentos, bebidas, móveis, arti- 
gos de vidro e, sobretudo, têxtil - e a imigração consolidam o Brás e o Bom Retiro como bairros industriais e de residência de operários. Vale destacar que as primeiras greves do país eclodiram nesses bairros. Elementos desse período estão presentes na paisagem dessas áreas ainda hoje (Figura 2).

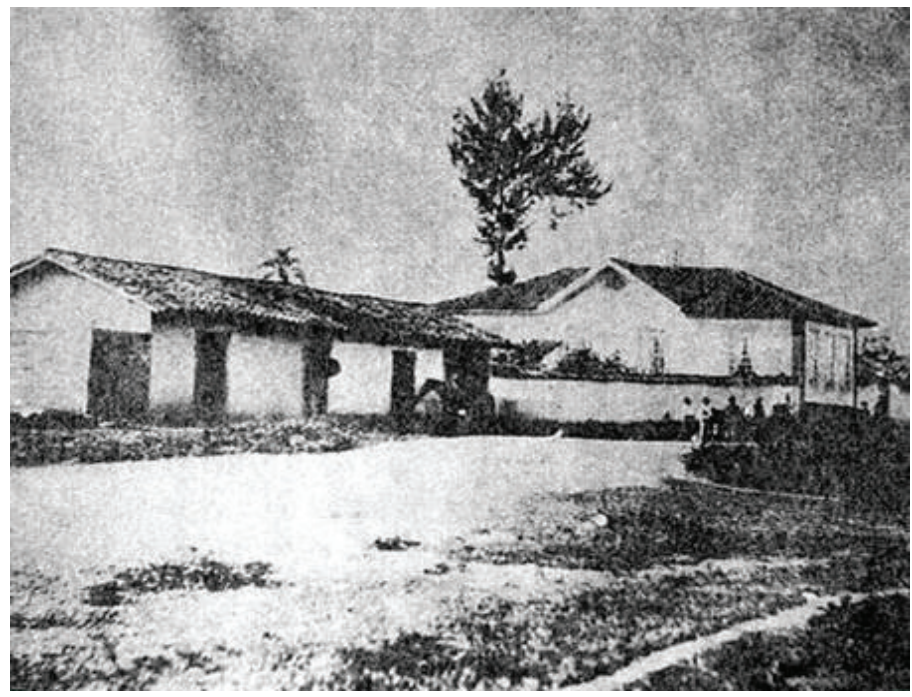

Figura 1- Chácara Bresser, 1862/1863: onde surgiu o bairro do Brás. Fonte: Foto de Militão Augusto de Azevedo. Associação Preserva São Paulo. Disponível em: $<$ http://www.preservasp.org.br/20 informativo.html > . Acesso em: 13 abr. 2014.

No terceiro período, da “decadência industrial” dos bairros (de 1930 a 1950), houve a migração das indústrias para outros bairros e a formação da especialização produtiva comercial em atividades do vestuário nestas áreas da cidade.

Já no quarto período, da consolidação da especialização no circuito espacial de produção de confecções (de 1950 a 1980), a atividade de fabricação e comércio do vestuário, trazida por imigrantes libaneses e judeus, foi reforçada pela forte migração dos nordestinos. Em seguida, há a ascensão dos imigrantes coreanos. Estes assumem a lógica do período da globalização que se tornará dominante posteriormente. 


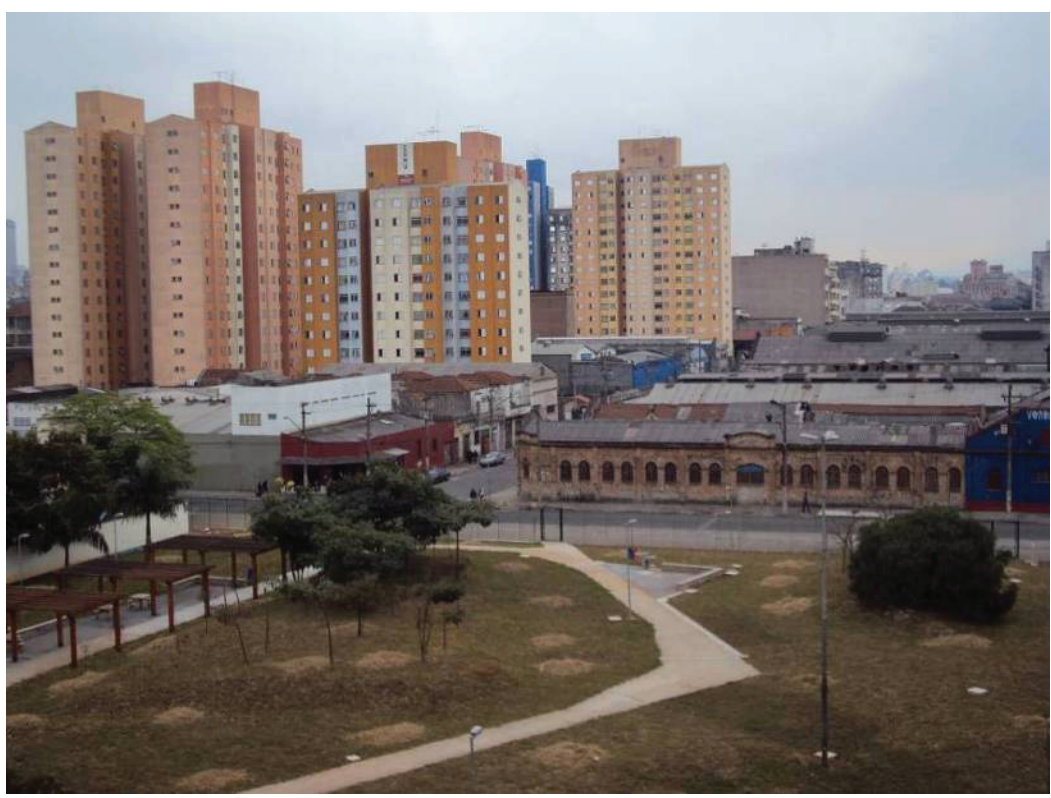

Figura 2 - Brás: no primeiro plano, as fábricas antigas (início do século XX) e, em segundo plano, os novos empreendimentos imobiliários.

Fonte: Foto da autora, em 15/8/2010.

No quinto período identificado, o da reorganização do circuito espacial de confecções (de 1980/1990 até os dias atuais), os coreanos assumem a especialização dos bairros, tanto na produção quanto na comercialização do vestuário. A partir da década de 1990, os elementos da globalização também são incorporados no processo produtivo das empresas do circuito superior de confecção, reverberando as atividades do circuito inferior. A ascensão da imigração indocumentada e mesmo documentada de bolivianos compõe parte desse novo período.

No Brás e Bom Retiro encontramos uma complexa rede de atores que criaram uma economia de aglomeração e proximidade, que possui grande centralidade, tanto para a produção quanto para o comércio. Este último chega a atrair consumidores de todo o Brasil. A especialização no circuito espacial do vestuário na metrópole, especialmente no Brás e Bom Retiro, teve uma renovação em seu funcionamento quando houve a incorporação, quase como regra, do sistema de subcontratação de oficinas, podendo atender aos novos conceitos do ramo, como o de fast fashion, que 
nada mais é que a aceleração do ritmo de criação, produção, distribuição e consumo. A necessidade da moda em substituir o design, a cor e o tecido das peças é a essência do crescimento das empresas que dominam o circuito da valorização econômica.

As funções urbanas do Brás e do Bom Retiro foram transformadas ao longo do tempo, mas sempre estiveram relacionadas às demandas da cidade e do território como um todo. Por isso, a forma e os conteúdos dos bairros exprimem a vida de relações de cada período geográfico, não estando restrito aos eventos locais.

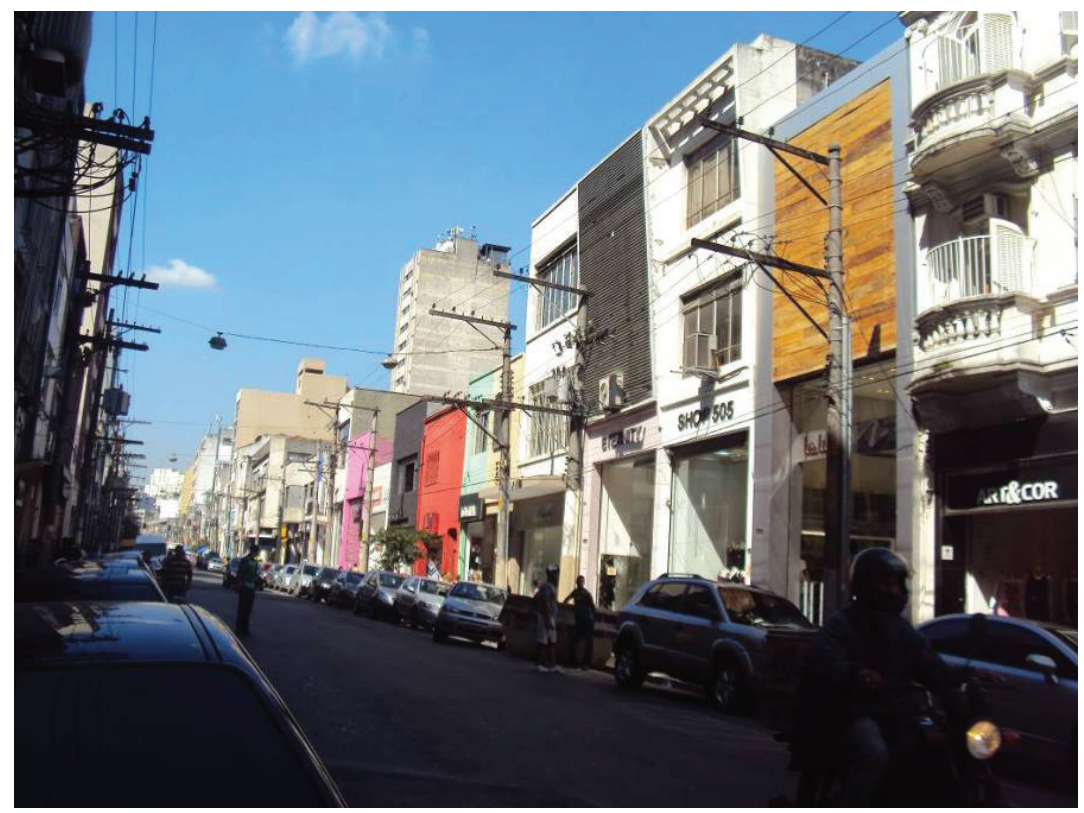

Figura 3 - Lojas de confecções na Rua José Paulino, no Bom Retiro.

Fonte: Foto da autora, em 18/4/2011.

A cidade de São Paulo torna-se um centro informacional, dada sua capacidade de produção, organização, distribuição da informação hegemônica e, ao mesmo tempo, um centro do uso da informação não hegemônica; ela também amplia seu papel na produção por meio do circuito inferior. A informação hegemônica, imposta pelas grandes empresas da "indústria da moda", coexiste com a informação usada como resistência 
nos microcircuitos das confecções, que abriga um grande volume de mão de obra. Ambos os polos compõem a dinâmica da economia urbana da metrópole e do território.

A centralidade informacional da metrópole também tem implicações para as empresas varejistas do ramo do vestuário. Por isso, essas empresas têm escritórios na cidade de São Paulo, acessando facilmente os serviços corporativos densamente concentrados na metrópole. Serviços de consultoria em marketing, logística, informática, auditorias e serviços jurídicos podem ser acessados pelo escritório central das varejistas. Ademais, a divisão técnica do circuito espacial de produção confere às empresas que comandam o circuito de acumulação a função de realizar as tarefas de maior exigência por qualificação; por esse motivo, elas demandam profissionais da área de moda, design, propaganda e gerenciamento. Por exemplo, em 2010, ${ }^{5}$ existiam cerca de 131 cursos de moda no Brasil (Moda, Design em moda, Estilismo, Gestão em moda, Negociação em moda, Tecnologia e produção de vestuário). A maioria deles concentrava-se nas regiões Sul e Sudeste, sobretudo em áreas com especialização produtiva em vestuário, como Santa Catarina com 23 cursos e Paraná com 12. O estado de São Paulo destaca-se com 39 cursos: 18 no interior do estado, 17 no município de São Paulo e outros quatro em municípios da Região Metropolitana de São Paulo.

Apesar da centralidade informacional da metrópole de São Paulo, e ainda que haja certa desconcentração das atividades produtivas, como de fabricação do vestuário, ela continua sendo um centro de produção de roupas e de comércio do território brasileiro, e os bairros do Brás e Bom Retiro são o lócus dessa centralidade.

\section{Centralidade do Brás e Bom Retiro no período técnico-científico-informacional}

Especialmente na década de 1990, houve grandes transformações no ramo do vestuário do país. Houve dispersão de parte da produção e do comércio. Entretanto, o município de São Paulo ainda possui forte centralidade na fabricação e no comércio de roupas, sendo o Brás e o Bom Retiro lócus dessa centralidade, pois abrigam parte das etapas do circuito espacial de produção de confecções, e mobilizam uma infinidade de trabalhadores e consumidores. 
O estado de São Paulo e o município de São Paulo perderam parte das atividades do ramo do vestuário conforme podemos verificar na Tabela 1 .

Tabela 1 - Pessoal ocupado na produção de confecção e acessórios (1994 - 2009).

\begin{tabular}{lccccc}
\hline & Município de SP & \% & Estado de SP & \% & Brasil \\
\hline $\mathbf{1 9 9 4}$ & 88319 & 22,9 & 150768 & 39,2 & 384952 \\
$\mathbf{1 9 9 5}$ & 79382 & 22,2 & 136937 & 38,2 & 358286 \\
$\mathbf{1 9 9 6}$ & 68925 & 19,7 & 124105 & 35,5 & 349530 \\
$\mathbf{1 9 9 7}$ & 58461 & 17,0 & 110542 & 32,2 & 343097 \\
$\mathbf{1 9 9 8}$ & 52850 & 15,3 & 104098 & 30,0 & 346499 \\
$\mathbf{1 9 9 9}$ & 56176 & 14,9 & 109253 & 29,0 & 376803 \\
$\mathbf{2 0 0 0}$ & 60854 & 14,8 & 118615 & 28,8 & 411272 \\
$\mathbf{2 0 0 1}$ & 59300 & 14,1 & 118608 & 28,2 & 421138 \\
$\mathbf{2 0 0 2}$ & 60912 & 13,7 & 121662 & 27,4 & 444365 \\
$\mathbf{2 0 0 3}$ & 59910 & 13,4 & 123125 & 27,5 & 448524 \\
\hline $\mathbf{2 0 0 4}$ & 65006 & 13,1 & 137719 & 27,8 & 495727 \\
\hline $\mathbf{2 0 0 5}$ & 68232 & 13,1 & 145400 & 27,8 & 522717 \\
\hline $\mathbf{2 0 0 6}$ & 73938 & 13,4 & 154911 & 28,0 & 552430 \\
\hline $\mathbf{2 0 0 7}$ & 78144 & 13,2 & 161903 & 27,4 & 591226 \\
\hline $\mathbf{2 0 0 8}$ & 81252 & 13,1 & 165714 & 26,8 & 618595 \\
\hline $\mathbf{2 0 0 9}$ & 81454 & 12,9 & 166620 & 26,3 & 632350 \\
\hline
\end{tabular}

Fonte: Rais-Caged; elaboração da autora, 2011.

O estado de São Paulo perdeu pessoal ocupado para os estados de Santa Catarina, Paraná, Minas Gerais, Ceará, Pernambuco e Rio Grande do Norte (Figuras 4 e 5). No entanto, quando analisamos os ocupados por municípios, verifica-se uma desconcentração para quase todo o território nacional, além disso, há a concentração em alguns municípios (Figuras 6 e 7), ou seja, há uma dispersão das atividades desse ramo, porém alguns lugares acabam aprofundando a especialização produtiva. Esse é o caso da própria cidade de São Paulo, mais precisamente os bairros do Brás e Bom Retiro. 


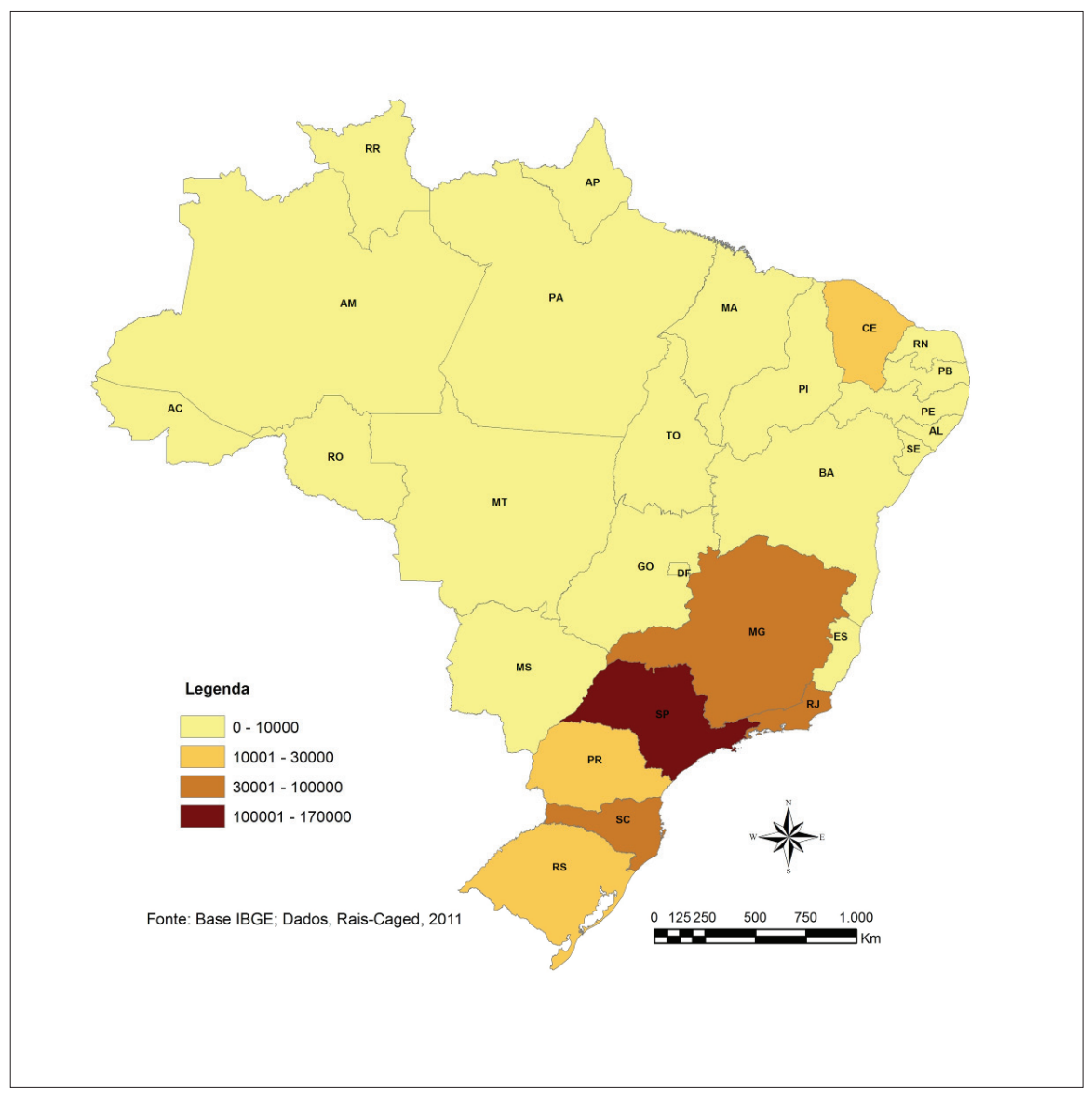

Figura 4 - Brasil: pessoal ocupado na produção de confecção e acessórios - 1994.

Fonte: Base IBGE; Dados Rais-Caged, 2011; elaboração da autora. 


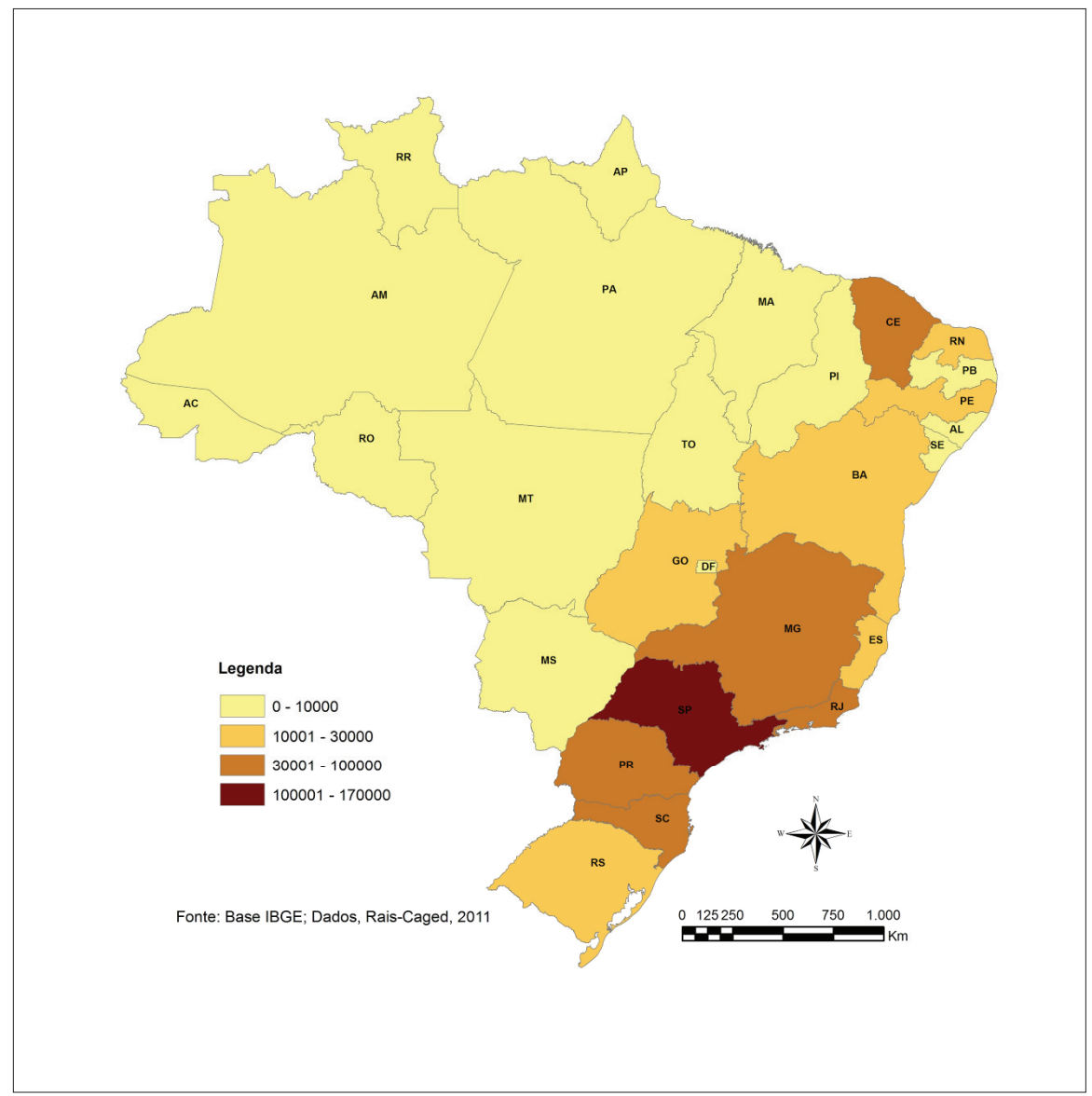

Figura 5 - Brasil: pessoal ocupado na produção de confecção e acessórios - 2009.

Fonte: Base IBGE; Dados Rais-Caged, 2011; elaboração da autora. 


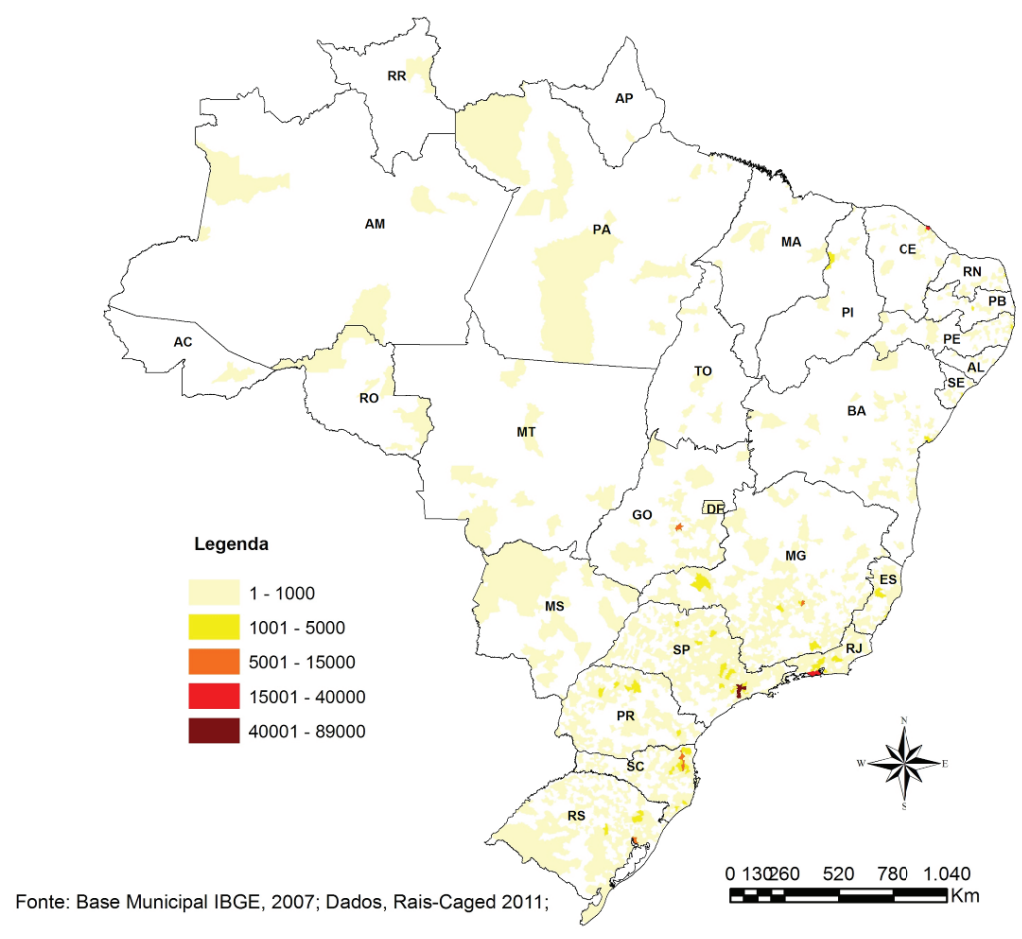

Figura 6 - Brasil: pessoal ocupado na produção de confecção e acessórios por municípios - 1994.

Fonte: Base IBGE; Dados Rais-Caged, 2011; elaboração da autora.

Segundo dados da Relação Anual de Informações Sociais (Rais) e do Cadastro Geral de Empregados e Desempregados (Caged), de 2010, o município de São Paulo em 1994 detinha 22,9\% do pessoal ocupado no ramo e, em 2009, esse número caiu para 12,9\%. Entretanto, em termos absolutos essa redução foi menos impactante, pois de 88.319 ocupados em 1994, passa para 81.454 em 2009 (redução de 7,80\%). 


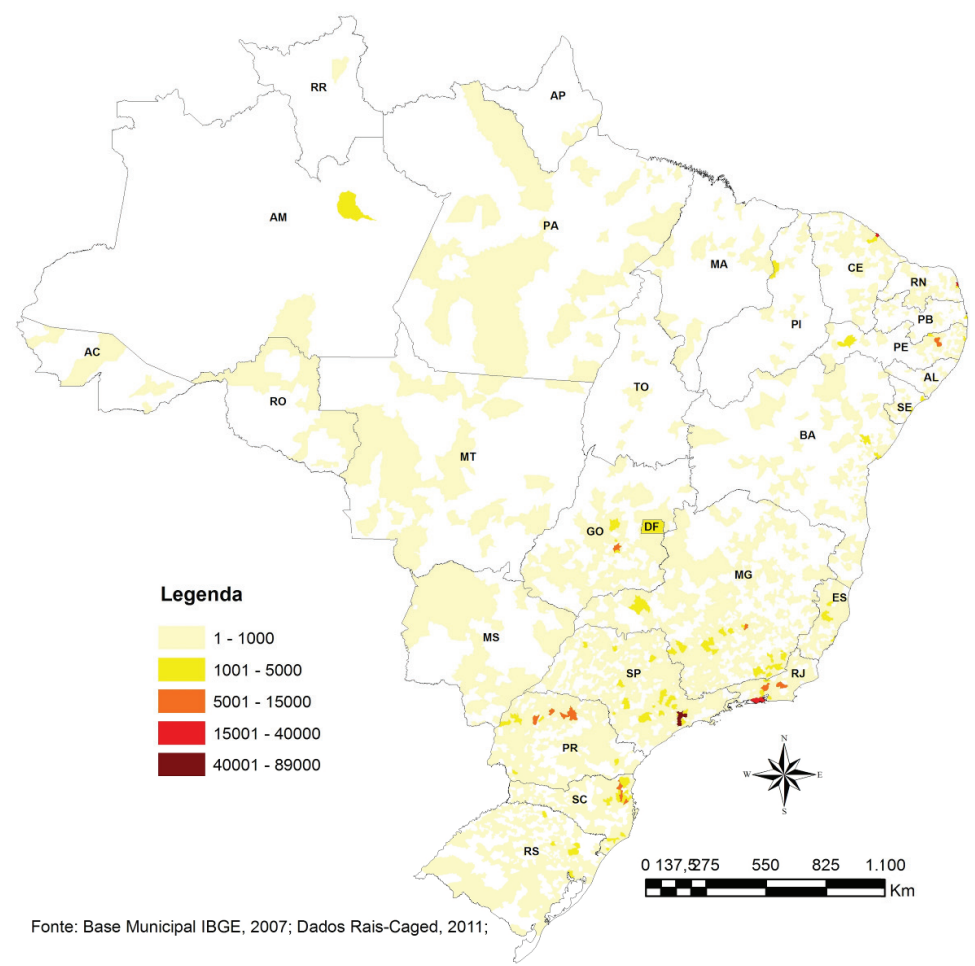

Figura 7 - Brasil: pessoal ocupado na produção de confecção e acessórios por municípios - 2009. Fonte: Base IBGE; Dados Rais-Caged, 2011; elaboração da autora.

No estado de São Paulo, a cartografia dos ocupados (Figuras 8 e 9) indica a consolidação nas cidades de Campinas, Americana, Santa Bárbara d'Oeste, Indaiatuba, Jundiaí e Limeira de ocupados com as atividades de confecção. Outras cidades do estado vêm se destacando também, como Sorocaba, São José do Rio Preto, Taguaí, Itapetininga, Avaré, Cerquilho, Bauru, Auriflama, Ribeirão Preto, além das cidades da Região Metropolitana de São Paulo como Guarulhos, Osasco e São Bernardo do Campo. O município de São Paulo destaca-se ainda como área de fabricação. 


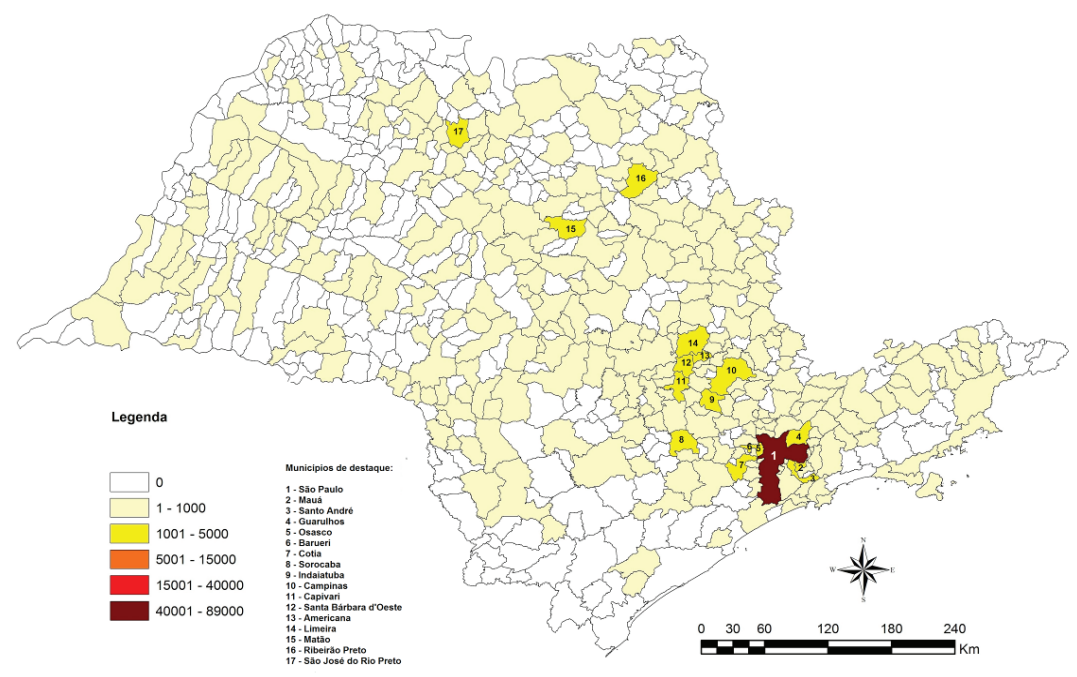

Fonte: Base Municipal IBGE, 2007; Dados Rais-Caged, 2011

Figura 8 - São Paulo: pessoal ocupado na produção de confecção e acessórios - 1994.

Fonte: Base IBGE; Dados Rais-Caged, 2011; elaboração da autora.

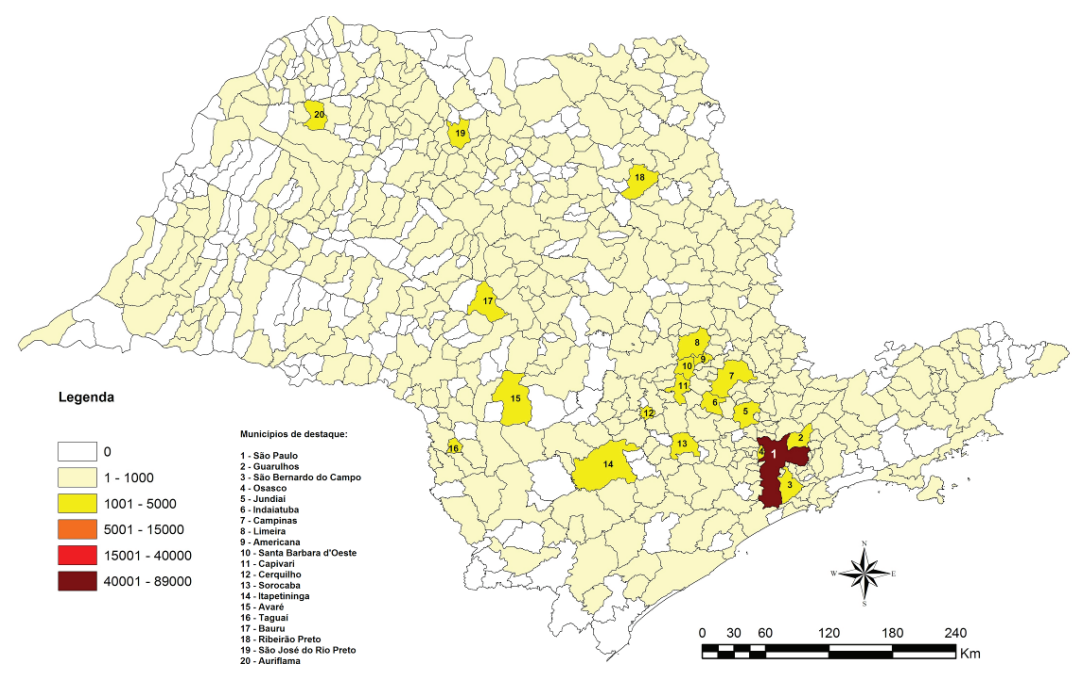

Fonte: Base Municipal IBGE, 2007; Dados Rais-Caged, 2011

Figura 9 - São Paulo: pessoal ocupado na produção de confecção e acessórios - 2009.

Fonte: Base IBGE; Dados Rais-CAGED, 2011; elaboração da autora. 
Apesar da relativa dispersão da mão de obra ocupada nas atividades do vestuário, a metrópole continua tendo significativa relevância. Cerca de 50\% da mão de obra ocupada concentra-se em 37 municípios do Brasil; entretanto, 12,88\% encontram-se em São Paulo, perfazendo 81.454 pessoas. A segunda cidade a abrigar mão de obra do ramo é Fortaleza com 5,64\%, correspondendo a 35.647 pessoas empregadas.

A dispersão da produção, especialmente da subetapa da costura do circuito espacial de produção do vestuário, ocorreu principalmente em virtude dos altos preços da mão de obra nas áreas de produção mais antigas como São Paulo, dos incentivos fiscais, tributários e territoriais oferecidos às empresas para se deslocarem para o Nordeste. O aumento da facilidade proporcionada pela maior densidade de transportes e comunicações também contribui com fatores fundamentais para o deslocamento da produção para outras regiões do território brasileiro e mesmo do estado de São Paulo.

Lencioni (1991), estudando a reestruturação da indústria na metrópole de São Paulo a partir do ramo têxtil, alerta que essas transformações têm como base o urbano, o industrial e o regional. A autora afirma que "a reestruturação urbano-industrial é condicionada pelos processos de concentração e centralização na reprodução do capital e sua manifestação se configura na desconcentração da metrópole” (1991, p. 15). Ela acrescenta ainda que a dispersão da produção e mesmo o crescimento de algumas cidades do interior paulista fazem parte do processo de metropolização, o que não significa a negação da metrópole, mas sim a conformação da macrometrópole paulista, pois a dispersão ocorreu no raio de até $150 \mathrm{~km}$ da capital.

A outra face do processo de dispersão da produção são as formas de centralização do capital como associações de empresas de capital privado, absorções e fusões e a subcontratação (Lencioni, 1991).

A reorganização da produção nos países centrais, em que o emprego do sistema de subcontratação de oficinas tornou-se comum, teve rebatimentos concretos no território brasileiro, tanto com relação às empresas multinacionais que passaram a usar esse sistema, substituindo as grandes plantas industriais, como as empresas de médio porte que também passaram a utilizar a subcontratação. Os comerciantes do Brás e Bom Retiro, em grande parte, igualmente passaram a terceirizar a etapa da produção. 
Esse movimento revela que há um aprofundamento da divisão técnica do trabalho, juntamente com o aumento da especialização territorial do trabalho em determinadas etapas da produção. O comando do lucro concentra-se nos agentes do comércio; por isso, em período recente houve um crescimento significativo das empresas de varejo do vestuário no Brasil e há uma tendência à formação de conglomerados das grandes marcas.

A organização atual da produção de confecção em São Paulo, embora haja uma tendência à dispersão das unidades de produção (oficinas), ainda está fortemente localizada: 37,36\% das oficinas no Brás e Bom Retiro, sendo 22,47\% no Brás e 14, 89\% no Bom Retiro. A Figura 10 mostra a concentração de oficinas nos distritos centrais e o espraiamento para a Zona Leste da cidade nos bairros de Belém, Tatuapé, Penha, Vila Maria, entre outros, além da expansão para a Zona Sul, especialmente para Itaim Bibi e Jardim Paulista.

Além da centralidade na atração de mão de obra, outras etapas do circuito espacial de produção do vestuário presentes no Brás e Bom Retiro também atraem fluxos. No Quadro 1, observa-se a origem dos consumidores que frequentam os bairros, e verifica-se a centralidade dessas áreas da metrópole para o território nacional, pois os dados indicam o poder de atração de fluxos do Brás e do Bom Retiro (Silva, 2012). Os circuitos inferior e superior marginal presentes nesta área da cidade atraem compradores de todo o território nacional.

Grande parte da produção do Brás e Bom Retiro atende ao mercado interno. Os lojistas têm dependência maior ao território, pois a área de especialização garante vantagens a esses atores: a convergência de profissionais, proximidade de matéria-prima (existência de fornecedores de tecidos, armarinhos, máquinas de costura, etc.), proximidade de trocas de informações, facilidade de contatar fornecedores e donos de oficinas. Há um limite para a distribuição das remessas de costura para a subcontratação, uma vez que o cálculo do custo da distância tem papel importante para esses atores; por isso, eles continuam produzindo no próprio bairro e na metrópole de São Paulo, não são agentes capazes de expandir a produção em todo o território nacional ou em escala mundial. 


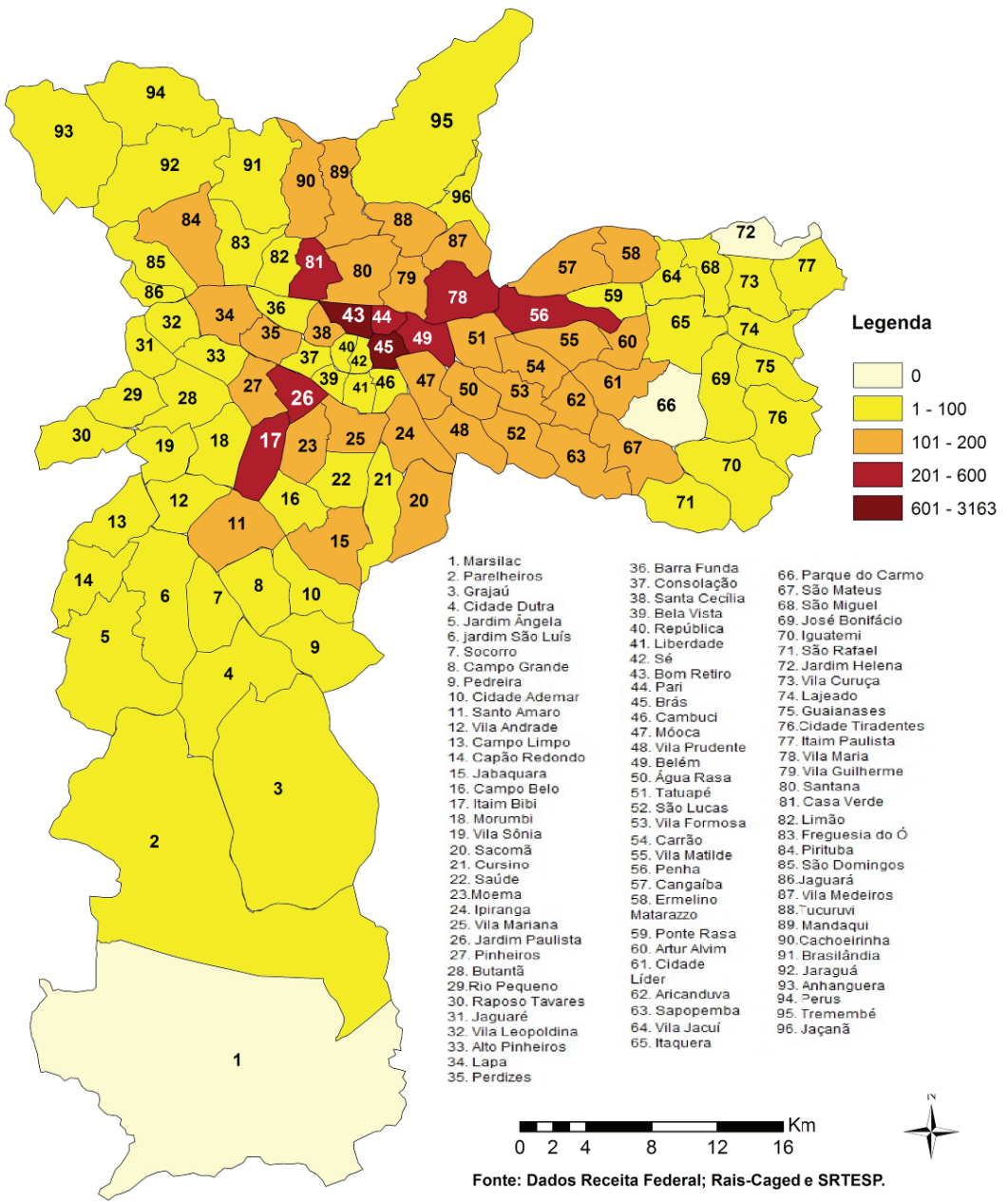

Figura 10 - Localização das oficinas do município de São Paulo por distritos - 2010.

Fonte: Dados da Receita Federal; Rais-Caged e SRTESP; elaboração da autora. 
Quadro 1 - Origem dos consumidores do Brás e Bom Retiro. ${ }^{6}$

\begin{tabular}{|l|l|l|}
\hline Estado & Quantidade & Cidade de origem \\
\hline Acre & 1 & Tarauacá \\
\hline Alagoas & 1 & Maceió \\
\hline Amapá & 1 & Macapá \\
\hline Bahia & 1 & Salvador \\
\hline Distrito Federal & 2 & Brasília \\
\hline Minas Gerais & 4 & Juiz de Fora, Campestre, Uberlândia \\
\hline Mato Grosso do Sul & 3 & Campo Grande, Nova Andradina e Chapadão \\
\hline Pará & 1 & Belém \\
\hline Paraíba & 1 & Campina Grande \\
\hline Piauí & 1 & Teresina \\
\hline Paraná & 6 & Cascavel, Colombo, Curitiba, Foz do Iguaçu \\
\hline Rio de Janeiro & 5 & Rio de Janeiro, Bom Jesus, Valença \\
\hline Rondônia & 1 & Porto velho \\
\hline Rio Grande do Sul & 1 & Caxias do Sul \\
\hline Santa Catarina & 2 & Florianópolis, Videira \\
\hline São Paulo & 38 & $\begin{array}{l}\text { Carapicuíba, São Paulo (17), Araçatuba, Bauru, Caju- } \\
\text { ru, Cosmópolis, Franca, Guarulhos, Itu, Jaú, Jundiaí, } \\
\text { Porto Feliz, Quatá, Ribeirão Preto, Santa Fé do Sul, } \\
\text { Santo André, Santos e Sorocaba. }\end{array}$ \\
\hline
\end{tabular}

Fonte: Dados sistematizados a partir de Pesquisa de campo.

Além disso, a concentração de vários comerciantes em um mesmo lugar possibilita a atração de mercado consumidor, que chega a ter centralidade em todo o território nacional, às vezes fora do Brasil, com mais intensidade para os consumidores do Sul e Sudeste. Segundo dados da Câmara de Dirigentes Lojistas (CDL) ${ }^{7}$ do Bom Retiro, os clientes desse bairro originam-se de todo o território nacional, especialmente do Sul e de cidades de até $100 \mathrm{~km}$ da capital.

Das 71 entrevistas realizadas com consumidores do Brás e Bom Retiro, ${ }^{8} 21$ pessoas indicaram que compram nestes bairros em razão dos preços; 10, pela variedade de lojas e produtos; 20 fazem suas compras em virtude da associação dos dois fatores: preços e variedade (de lojas e produtos); 10 afirmaram que compram nestes locais em razão de todos esses motivos (preço, variedade de lojas e produtos e produtos da moda).

A possibilidade de encontrar todos os tipos de produtos (vários modelos, sempre atualizados com a moda, e com preços mais reduzidos em razão do caráter atacadista dessas lojas) e mesmo produtos específicos 
para lojistas, como artigos para vitrines e mostruário, condicionam a própria existência dos comércios do Brás e Bom Retiro.

Dessa forma, a metrópole que se caracteriza pela produção de informação, a metrópole informacional, é lócus da produção fabril de atividades tradicionais como o ramo do vestuário.

O período técnico-científico-informacional é definido por Santos (2008) como o período em que a informação é central nas relações entre os grupos sociais e entre esses com o território. Nesse sentido, os fragmentos da cidade são mais ou menos produtores de informação, mas essa informação pode ser aquela de ordem global ou aquela vinculada à proximidade e à vida de relações, ou seja, esta última é composta por informações não hegemônicas, como no caso de grande parte das oficinas, dos comércios e dos consumidores do Brás e do Bom Retiro.

\section{Conclusões}

Apesar de todos os discursos construídos sobre as áreas antigas deterioradas da cidade de São Paulo, os bairros do centro são dinâmicos do ponto de vista da economia do circuito inferior. O Brás e o Bom Retiro, por meio da especialização produtiva no ramo do vestuário, tornam inegável o papel desses fragmentos da cidade na própria conformação e consolidação da metrópole. Esses bairros transformaram-se em referência nacional e até internacional no fornecimento de confecções.

A divisão territorial pretérita, que decorreu da indústria têxtil, forneceu elementos para as novas atividades no Brás e Bom Retiro. Muitos comerciantes de vestuário compram tecidos ali e fabricam suas próprias peças. A proximidade entre os produtores, a disponibilidade de mão de obra com conhecimento da costura (rotatividade da mão de obra entre os confeccionistas), além do crescimento de lojas auxiliares à produção como as de aviamentos, embalagens, artigos para vitrines ("manequins"), entre outros, confirmaram essas áreas da cidade como especializadas no circuito espacial da produção do vestuário; a fabricação e o comércio são intensos nos próprios bairros.

O Brás e o Bom Retiro revelam a presença do circuito inferior da economia urbana da cidade de São Paulo, tendo mantido o caráter de espaço de imigrantes. É justamente nos espaços “deteriorados” da metrópole que as atividades do circuito inferior tomam forma, pois uma das caracte- 
rísticas desse circuito é o uso de lugares onde os baixos custos e o acesso ao consumidor são as regras de sua existência.

A população de imigrantes estabeleceu uma nova vida de relações, mais que em outros momentos, e evidencia a interdependência dos lugares no período da globalização. Os lugares são ressignificados a partir de suas materialidades preexistentes. Na compreensão do circuito produtivo das confecções, identificamos como esses bairros da metrópole acolhem circuitos que são o avesso da metrópole informacional, e ao mesmo tempo, conectam-se totalmente a ela.

Hoje o Brás e o Bom Retiro atraem pessoas de todo o Brasil em virtude do comércio de roupas populares. As lojas desses bairros e a Feira da Madrugada (Brás), em particular, trouxeram para esses lugares uma enorme efervescência, agora com novas variáveis em questão, como a nova organização das empresas, a divisão técnica intrafirma, a crescente financeirização da atividade e o uso de mão de obra imigrante indocumentada. Esse intenso dinamismo contraria as teses do abandono do centro e da intensa deterioração presente. Muitas vezes, confunde-se a estética do bairro (técnicas envelhecidas no contexto da metrópole informacional), que em grande medida revela a frequência no local de uma população pobre, com a falta de dinamismo econômico e uma enorme deterioração.

Muitos agentes compõem a cena cotidiana desses bairros, desde os modernos shoppings de confecções no Brás até o comércio intenso nas ruas durante a Feira da Madrugada e o famoso comércio de rua, na José Paulino, no Bom Retiro. Esses fragmentos da cidade podem ser considerados "fábricas de vestuário" do Brasil no período da globalização. Essa atividade ganha proeminência, sobretudo a partir da década de 1990.

Além de metrópole das atividades informacionais sofisticadas, associadas ao circuito superior da economia urbana, podemos reconhecer São Paulo como a metrópole das atividades ligadas ao circuito inferior da economia, uma vez que a modernização foi responsável pelo aumento das profissões de alto nível, relacionadas às atividades quaternárias e também ao movimento de precarização do trabalho.

No caso do circuito espacial do vestuário, o circuito inferior da produção vem se articulando cada vez mais ao sistema produtivo das grandes e médias empresas, isto é, a subcontratação de oficinas de costura coloca o circuito inferior sob domínio do circuito superior. Há uma especialização do subsistema superior em atividades sofisticadas e do subsistema 
inferior em atividades relacionadas diretamente à costura. A cidade cria e condiciona o exercício de tais atividades, sejam elas modernas ou não modernas, mas sempre articuladas pelos nexos da economia política da cidade.

O Brás e o Bom Retiro acompanharam o movimento de transformação da metrópole. Embora envelhecidos, continuam tendo centralidade nas atividades econômicas, não apenas na metrópole, mas no território brasileiro, o que indica que a centralidade de São Paulo é composta também pelos seus bairros especializados como o Brás e o Bom Retiro, mesmo no período técnico-científico-informacional.

\section{Notas}

1. Esse artigo é parte dos resultados da pesquisa de doutorado realizada da no IG-UNICAMP entre 2008 e 2012 com financiamento FAPESP (Processo n ${ }^{\circ}$ 2008/06590-6) e sob orientação do $\operatorname{Prof}^{\circ} \operatorname{Dr}^{\circ}$ Marcio Cataia.

2. Segundo Santos (2004), a teoria dos dois circuitos da economia urbana busca explicar como as cidades dos países periféricos, como o Brasil, funcionam a partir de dois subsistemas urbanos: o subsistema superior - composto pelas grandes empresas, bancos, atividades ligadas ao ramo da alta tecnologia - e o subsistema inferior - composto pelas atividades de pequena dimensão, com o uso de mão de obra intensiva e que se cria e recria com pouco capital. A população da cidade, independente de sua classe de renda, possui necessidades permanentes. Em razão da existência de trabalho perene e bem pago de um lado, surge o circuito superior; por outro, a existência de trabalho de baixa remuneração e intermitente demanda a criação de formas de sobrevivência por grande parte da população. Assim, surge o circuito inferior. A distinção desses dois circuitos ocorre pelo uso de capital, tecnologia e organização. Destaca-se que não se trata de uma dicotomia e sim de polarizações.

3. O conceito de "vida de relações" foi cunhado por George (1968) para referir-se às solidariedades internas aos lugares.

4. Os três primeiros períodos identificados têm como base a pesquisa de Martin (1984).

5. Segundo dados do Guia ABRIL, de 2010.

6. Foram aplicados 45 questionários no Brás e 26 no Bom Retiro, nos dias 18/8/2011 e 19/9/2011.

7. Roteiro de entrevista encaminhado e respondido pela CDL - Bom Retiro, através de correio eletrônico, em 13/7/2010.

8. As entrevistas foram feitas durante a Pesquisa de campo. 


\section{Referências}

ANDRADE, M. M. Brás, Mooca e Belenzinho: "bairros italianos" na São Paulo além-Tamanduateí. Revista do Departamento de Geografia, v. 8, p. 97-102, 1994.

GEORGE, P. A ação do homem. São Paulo: Difusão Europeia do Livro, 1968.

HARVEY, D. O trabalho, o capital e conflito de classes em torno do ambiente construído nas sociedades capitalistas avançadas. Tradução de Flávio Villaça. Espaço e Debates, n. 6, p. 6-35, junho/setembro, 1982.

KONTIC, B. Inovação e redes sociais: a indústria da moda em São Paulo. Tese (Doutorado em Sociologia) - Faculdade de Filosofia, Letras e Ciências Humanas, Universidade de São Paulo, São Paulo, 2007. 157f.

LANGENBUCH, J. R. A estruturação da Grande São Paulo: estudo de geografia urbana. São Paulo: IBGE (Série Biblioteca Geográfica Brasileira), 1971.

LENCIONI, S. Reestruturação urbano-industrial: centralização do capital e desconcentração da metrópole de São Paulo - a indústria têxtil. Tese (Doutorado) - FFLCH-USP, São Paulo, 1991. 286f.

MARTIN, A. R. O bairro do Brás e “a deterioração urbana”. Dissertação (Mestrado em geografia) - Departamento de Geografia da FFLCH-USP, São Paulo: 1984. 187f.

MARTIN, A. R.; FRUGÓli JÚNIOR, H. Braz do Brasil, Braz de todo o mundo. Revista do Departamento de Geografia, n. 6, p. 105-111, São Paulo, Universidade São Paulo, 1992.

MONTENEGRO, M. R. O circuito inferior da economia urbana na cidade de São Paulo no período da globalização. Dissertação (Mestrado) - Departamento de Geografia, FFLCH-USP, São Paulo, 2006. $205 f$.

. Circuito inferior central na cidade de São Paulo em sua relação com a densidade de fluxos e com o meio construído. Mercator - Revista de Geografia da $U F C$, ano 08, n. 15, 2009.

SANTOS, M. O espaço dividido: os dois circuitos da economia urbana dos países subdesenvolvidos. São Paulo: Edusp, 2004.

- Técnica, espaço, tempo: globalização e meio técnico-científicoinformacional. São Paulo: Edusp, 2008. . Por uma economia política da cidade. São Paulo: Edusp, 2009.

SILVA BERNARDES, A. M. A contemporaneidade de São Paulo: produção de informações e reorganização do território brasileiro. Tese (Doutorado) Departamento de Geografia, FFLCH- USP, São Paulo, 2001. $282 \mathrm{f}$.

SILVA BERNARDES, A. M.; CASTILLO, R. Dinámicas metropolitanas en la era de la globalización: la promoción inmobiliaria para empresas en la ciudad de São Paulo. EURE (Santiago), v. 33, p. 45-56, 2007.

SILVA, S. C. da. Circuito espacial produtivo das confecções e exploração do trabalho na metrópole de São Paulo: os dois circuitos da economia urbana nos 
bairros da Brás e Bom Retiro (SP). Tese (Doutorado) - Departamento de Geografia do Instituto de Geociências da Unicamp, Campinas, 2012. 327f.

SPOSITO, M. E. B. Dinâmica econômica, poder e novas territorialidades. In: SPOSITO, E. S. (Org.). Dinâmica econômica, poder e novas territorialidades. Presidente Prudente: GAsPERR,1999.

Silvana Cristina da Silva - Possui Graduação em Geografia pela Universidade Estadual de Campinas. Mestrado e Doutorado em Geografia pela mesma Universidade. Atualmente é professora da Universidade Federal Fluminense - Polo Universitário de Campos dos Goytacazes.

Recebido para publicação em 5 de janeiro de 2015 Aceito para publicação em 18 de fevereiro de 2015 